\title{
TOWARDS A DIGITAL HERITAGE: EVALUATING METHODS OF HERITAGE INTERPRETATION, DIU TOWN - A CASE STUDY
}

\author{
ANISHA MEGGI \\ De Montfort University, Leicester, UK.
}

\begin{abstract}
The process of heritage interpretation through the digital simulation method has been tested as an environment required for the process of restoration, conservation and design for the future of a heritage site. However, this paper questions whether the digitally collected data and heritage interpretation/ representations which are a useful tool for professionals like architects and developers lead to critical evaluation, inspiration and engagement for the heritage owner/layman. The former Portuguese colony of Diu Island, UT, India, presents an array of tangible and intangible heritage featuring a Portuguese fortification and churches along with the historic urban fabric of Diu Town as a complex and historically relevant primary case study. The various methods of heritage data capture and the opportunities the outputs create for interpretation/representation will be evaluated in this paper. The methods of capturing data to interpret heritage values covered in the paper are traditional building survey, laser scanning, photospheres and photogrammetry. The discussion begins with inherent advantage and disadvantages within each method of heritage data capture, ways in which the heritage owner and the local community can be active participants in the data-collection process and, most importantly, the output of the datacollecting techniques. This leads on to the core of the paper which questions the output of the collected data and its wider opportunities for representation of the values of heritage to heritage owners/layman. The paper evaluates the outputs of the digitally/non-digitally collected data to understand the opportunities of heritage representation that can allow for layman engagement and inspiration towards heritage interpretation and conservation in a part of the world where such practices have not been common in the past. Furthermore to gain professional advise on structural and design work to adapt or conserve the heritage structure.
\end{abstract}

Keywords: architectural representation, digital simulation, Diu Island, heritage architecture.

\section{INTRODUCTION}

The former Portuguese colony of Diu Island sits on the south coast of Gujarat, India. It has a vast array of tangible heritage in the form of a large 16th-century Portuguese fortification, several churches and the urban town with the same name called Diu Town. The Portuguese fortification, churches and other religious edifices on the island have experienced academic focus by the likes of Rossa [1], Shokoohy [2-4] and other academics in the field [5-7]. However, it is the Town of Diu with its distinct colonial flavour that is currently dangerously under threat of being demolished due to new developments on the island and lack of heritage knowledge among local and diaspora heritage property owners.

\subsection{Architecture in Diu Town}

The architecture of Diu Town has been mentioned very rarely, one such paper being 'The Island, its Architecture and Historic Remains', where the authors state, 'the Portuguese houses give the narrow lanes and urban and village squares a distinctive Mediterranean flavour' [2]. In a field trip to Diu Island, during May-June 2017, Diu Town was closely observed for its privately owned heritage architecture, the decisions taken for the heritage properties and the overall effect of modern developments within the town (shown in Figs. 1-3). 

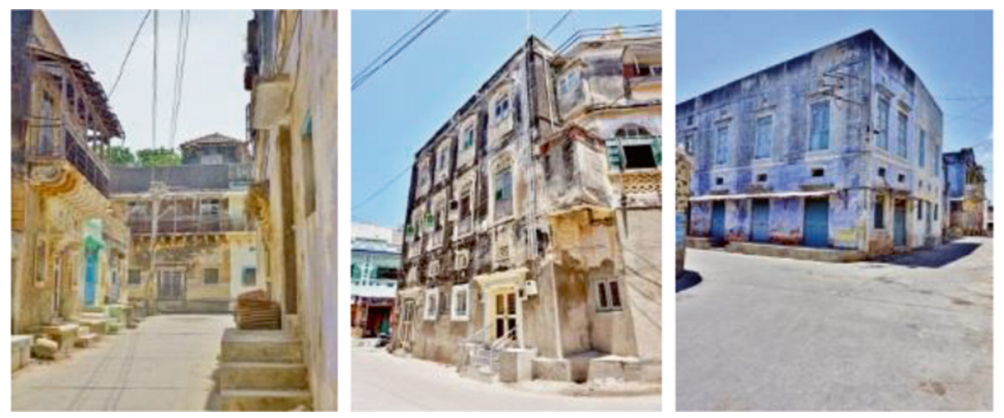

Figure 1: Some typical streets of Diu Town (Source: Meggi, A. 2017).
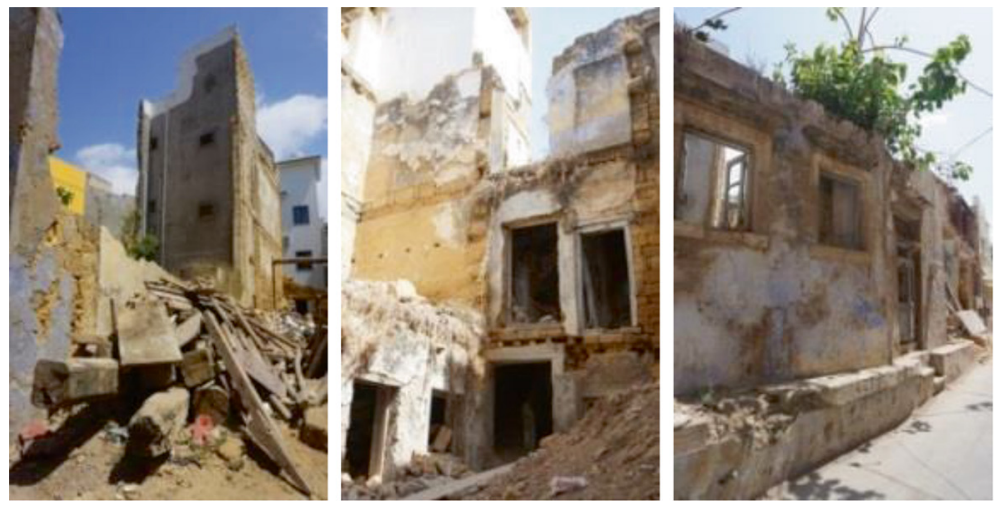

Figure 2: Deteriorating heritage structures of Diu Town (Source: Meggi, A. 2017).
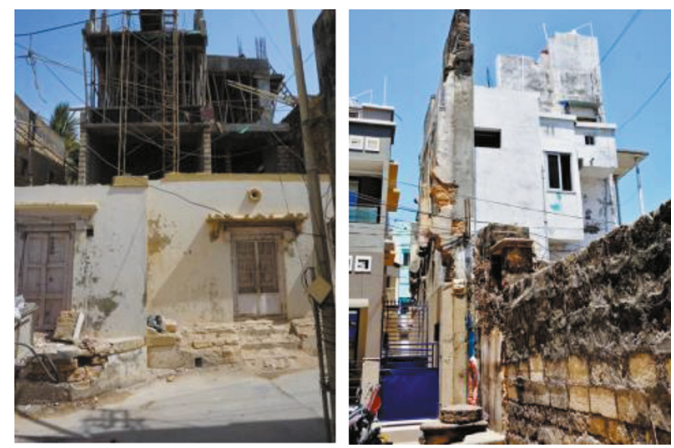

Figure 3: Remains of heritage ruins (Source: Meggi, A. 2017).

\subsection{Owners of heritage architecture in Diu Town}

The architectural heritage owners of Diu Town can be divided into two groups; those that live in the town - the local heritage owners - and those that live outside of the town and island, in other Indian cities or in most cases internationally - the diaspora. Most diaspora members are products of the employment-based migration route formed when the Portuguese Empire 
was still functioning in Africa and the Indian subcontinent. It can be said that the majority of diaspora members currently reside in Lisbon [8,9], London and Leicester; however, there are still a significant number of Diuenses who still reside in areas of Mozambique and other parts of the world.

Whilst local heritage owners maintain the properties they live in, the diaspora members have had to lock their properties up; due to neglect, the property becomes structurally unsafe, disintegrates and then is demolished. Heritage properties have a strong significance as the tangible artefacts passed down by the ancestors hence are not easily sold off. Diaspora heritage owners rarely sell their heritage property but are seen to demolish and rebuild on the same plot of land. However, it was noticed that is not always a case of the heritage property becoming structurally unsafe, which leads to the demolition and building of a new property. It has been observed that the heritage properties are demolished and rebuilt because they are unable to accommodate for modern lifestyles which include large electrical appliances and furniture. The diaspora members have found the need to accommodate the modern lifestyle that they lead in their western home countries. Local heritage owners who are financially stable and wealthier have chosen to demolish their heritage properties copying their diaspora counterparts in what they feel is moving forward by accommodating modern lifestyles.

\section{ISSUES WITH PRIVATE HERITAGE IN DIU TOWN}

It can be said that keeping the heritage properties within the family and not selling it to outsiders is evidence of the importance and value that the owners give to their heritage properties. However, the non-sale of these properties is not enough to safe keep the identity of the town as the way in which the heritage property is being treated; neglect and demolition is the largest reason there is a loss of place, identity and slow eradication of heritage culture, tradition and the unique essence of place that the town once used to have. Private heritage can be a contested area, as the whole idea of owning a property means that one can make their own decisions regarding the property rather than be restricted or told how to treat the property by the local council or government sectors. Having said this, urban heritage is said to be owned by a collective group of people; a specific community or even the entire human population. It means that private heritage owners have some kind of moral, and in some countries legal obligations to conserve, preserve or modify their heritage without damaging/destroying the essence or character of it.

In the case of Diu Town, there are several issues that have been observed that contribute to the neglect and demolition of heritage properties. The first reason, in no particular order, is that the diaspora heritage owners are geographically away from their properties, and some from families for several years. Hence, the property is neglected and under-maintained. It is also noted that due to the property being an heirloom it is not sold out of the family and left to decay instead. Another reason as mentioned earlier is the necessity to accommodate for lifestyle advancements, in the form of electrical equipment like washing machines etc. The most interesting problem that results in the demolition of perfectly habitable heritage properties is the lack of a design architect/firm on the island or in close proximity. Overall, it can be said that there is a lack of knowledge of heritage practise and conservation issues especially for non-monument and privately owned properties. The cultural, historical and economic values of the private property which enable the design architect, planner or developer to take on the project and make decisions that are historically and culturally suited for the contextual situation are lacking for the private heritage of Diu Town due to no recordings/representations of the heritage properties. 
On the whole, heritage of any kind is indeed valued by the owner, but their decisions regarding the heritage do not always reflect the care and value they have. Hence looking closer at the decisions and reasons behind the demolition or neglect of the heritage property can lead to the underlying issues that can play an influential role in the active conservation, preservation and overall maintenance of the heritage property. Therefore, the next two sections outline the various methods by which heritage can be captured, digitally/non-digitally simulated and interpreted/represented for the benefit of the heritage owners and their future generations to continue to be aware of the historical and cultural importance of their heritage. In addition, architects and developers should be aware of the overall heritage values in order to make sympathetic decisions when modifying, rebuilding or preserving the heritage property.

\section{METHODS OF CAPTURING AND INTERPRETING HERITAGE ARCHITECTURE}

In this section, four methods of capturing the architectural heritage of Diu Town will be discussed and critically evaluated for the capturing methods' ability to engage heritage owners/ layman during capture and ability to interpret their heritage. Overall, the following methods of capturing heritage data will be evaluated for (1) engagement of laymen (diaspora and local heritage owners), (2) potential to be used to inform professionals like architects and planners of heritage values site- and context-specific heritage information and (3) the feasibility of conducting each method within Diu Town and overall cultural context.

\subsection{Traditional methods of surveying architecture}

Advantages: (1) Laymen/owners can be engaged in the process of collecting and helping the professional conduct the building survey with some training given. (2) The conservationist/ architect has the ability to understand the atmosphere, feeling of the space as a pose to just the three-dimensional spatial values. (3) Interpretation of hand drawings/sketches can be engaging and promote active responses due to the fact that hand drawings have a certain type of fine art/painting quality that invites comments and encourages conversation between laymen. Overall, this method allows for the first-hand experience of the tangible and intangible aspects of the heritage urban environment, engagement of the professional with local people through observation and active process of that information when recording that information. Disadvantages: (1) Laymen/owners are not always available to take part; many owners are diaspora members in the case of Diu Town and many locals are only educated until primary or mid-secondary school. (2) Due to time constraints and the purpose of the orthographic drawing, all the information is impossible to record; hence this method is subjective and missing information is common for the conservationist and their specific purposes. The drawings produced may not be the technical, orthographic ones that can be worked and may need further processing. (3) Laymen may not connect with the drawings as one might feel - the drawings can be presented at a public space within the town for maximum engagement and interest to be created. The most prominent disadvantageous aspect of traditional hand surveying is the time taken for the surveying and construction of orthographic drawings which can be subjective. There is also a large risk of incomplete data in traditional hand surveying. This is along with the restricted accessibility to measure taller structures or intricate detailing.

This method might at first seem tedious and difficult. But for the case of Diu Town which has never been recorded for its physical heritage structures and the overall feeling/essence and flavours of the town, this method of hand surveying that is accompanied by sketches, 
paintings and recordings of other metaphysical elements can be a starting point for neverbefore recorded heritage urban environments as illustrated in Fig. 4. These informal drawings of onsite observation of tangible and intangible heritage would initiate the process of other capturing techniques for formalized usage (e.g. laser scanning, photogrammetry).

\subsection{Photogrammetry}

The basics of this method require a group of photographs of the same object, in this case, the façade of a heritage building or part of an interior that are all overlapped with one another, coming together on specialist software to create a three-dimensional point cloud model. The most well-known project that uses photogrammetry is that of the Bamiyan Buddha statues that were destroyed by explosive attacks [10]. In the first field trip to Diu Island, May-June 2017 , this method was tested by taking photographs of a traditional Indian door moulding found at many main entrances of heritage properties, Fig. 5.

Advantages: (1) Laymen, both diaspora and locals, can aid the pool of photographs needed to construct the photogrammetric model. (2) Photogrammetric models can be used to extract orthographic drawings and because the models are photorealistic there is no subjectivity. (3) Photogrammetric models and processed orthographic drawings can be processed further for laymen interpretation. Disadvantages: (1) Missing information needs to be addressed by the professional creating the model; the model can be incomplete when existing photographs do not cover the entire structure. (2) A professional who is competent with the photogrammetric

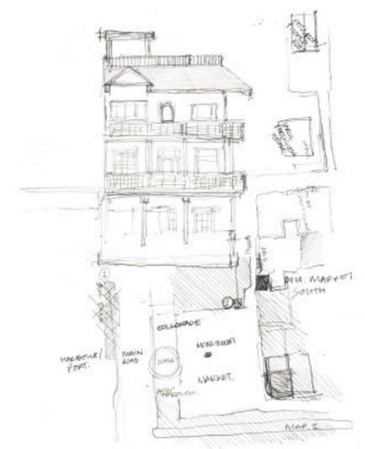

Figure 4: Initial sketch of heritage structure, Diu Town, May-June 2017 (Source: Meggi, A. 2017).
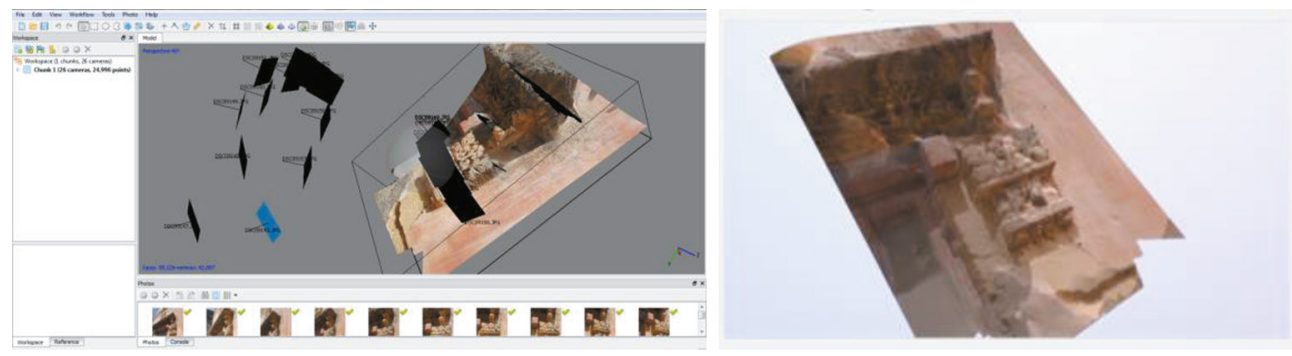

Figure 5: Agisoft software environment and final model (Source: Meggi, A.2017). 
software is required to process the photographs into models and extract/create the orthographic models. The outcomes can be used for further conservation work on the heritage structure. (3) Digitally generated photogrammetric models have issues of virtual models that are distant and hard to emotionally or physically connect with for laymen to interpret. This method requires a group of heritage owners to be formed and to supply images for photogrammetry to take place. Whilst this method creates a sense of community for those contributing, the engagement of a larger laymen population and interpretation of virtual/digitally produced drawings/models is distant and detached. This method can possibly be used by the professional hand surveying as a method to capture the detailed façade/s interiors as well as to obtain measurements from.

\subsection{Photospheres}

A series of photographs can be taken using the most basic of smartphones, and a mobile application then processes the images into a photo-realistic walkthrough of the interiors, very similar to Google Street View [11, 12]. The photographs are stitched into 360-degree photospheres, which are grouped together to create a large space and rooms linked to one another. Advantages: (1) Layman, diaspora and locals can engage with this method easily with the use of their smartphones, taking photographs of their heritage homes using a mobile application that can process the photographs into a Google Street view style interior walkthrough. (2) Architects and conservationists can get a good understanding of the feeling/ atmosphere of the space through an immersive experience from a distance. (3) In advanced Photosphere applications, it is possible to overlay the immersive experience with further videos, photographs and textual information to aid interpretation and understanding of the space. Disadvantages: (1) The layman may not own a smartphone, or their phone might not have the ability to host the mobile application. The elder heritage owners of the town may not have the skills to use a smartphone or the mobile application. (2) Architects/conservationists do not have an outcome in the way of orthographic drawings/models that would be useful for future work on the property. (3) The process of overlaying further information is possible on some commercial Photosphere mobile applications that have higher financial implications. Photospheres are considered entertaining and can be successful in engaging laymen/owners and let others experience distant, non-accessible heritage sites. This method would take a considerable amount of effort to form a group of heritage enthusiasts, who need be trained to carry out this method. However, the outcomes would be minimal for architects and conservationists; hence this method is ruled out completely for Diu Town within this evaluation.

\subsection{Laser scanning}

This is probably one of the most technologically advanced methods with which the site can be captured for its textures, colours and measurements. 'The collection of data points is generated by a 3D scanner that rotates while emitting a laser that measures the distance to points on surrounding surfaces' [13]. Each scanning scene has to be set up with reference points that can be seen in the next scan and were visible in the previous scan. This process of reference points being visible and overlapping in successive scans is what enables registration and the collation of the scans into one complete model. The setting up of the reference points takes some time on site even if there has been prior strategic planning of placement. Each scan then takes the laser scanner approximately 6-10 min to capture the 360-degree surroundings. 

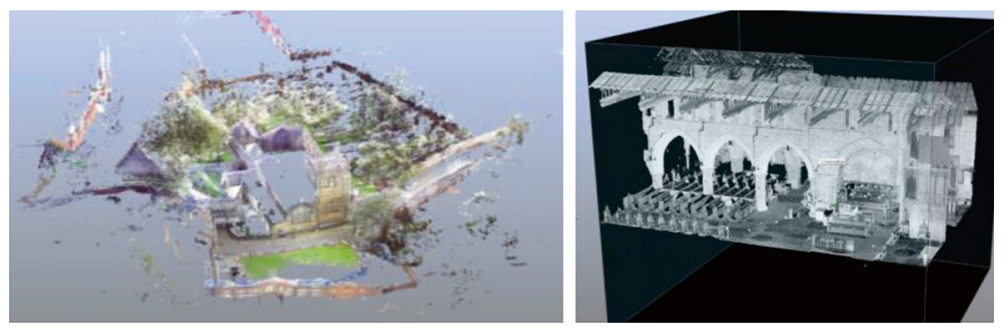

Figure 6: Point cloud models of St Mary de Castro, left: site plan and right: section (Source: Meggi, A. 2016).

The maximum distance between two scans has been noted as being less than $20 \mathrm{~m}$ so that the reference points are registered during the post-processing stage.

Advantages: (1) Laymen within the process can review/observe the scans on the digital display of the laser scanner. Owners of the property can gain a set of detailed orthographic drawings and interior views of perspectives/angles the property could not otherwise be viewed as. (2) Architects and conservationists have a set of highly detailed models/drawings that can be used for future conservation work. (3) Laymen can be involved in the interpretation of post-process outcomes of the laser scans such as interactive digital models, perspective drawings/visualizations etc. Disadvantages: (1) The process of laser scanning compared to the aforementioned methods of capture is one which has the least layman engagement as it needs a trained professional to work with the laser scanner - maybe training the laymen to help with setting up the scene with reference balls. (2) Architects and conservationists need to be trained to not only scan but also deal with the post-processing stages. (3) Interpretation of virtual models and drawings/representation can be disconnected and distant for laymen. Figure 6 shows the laser scanning outcome carried out in St. Mary de Castro, Leicester, UK, that enables the vital experience of the capturing and post-processing issues involved in laser scanning. Along with this, the experiences of the pilot research trip to Diu Town in May-June 2017 help to conclude that logistically getting large or expensive equipment like laser scanners to a remote destination, Diu Island, is going to be difficult. Furthermore, high temperatures and risk of damage, loss or theft of expensive kit make this process difficult to undertake in Diu Town.

\section{CAPTURING, INTERPRETING AND REPRESENTING HERITAGE OF DIU TOWN}

\subsection{Recording and capturing}

The feasibility discussion in Section 3 informs the following conclusion. It was found that the methods of capture all have their own inherent qualities of; engaging laymen during capturing process, outcomes that are appropriate for architects/conservationists to use as part of future rebuilding etc., and outcomes that are appropriate for laymen interpretation of heritage. Furthermore, the evaluations in Section 3 start to give form to a stage by stage method that involves each capture method as a particular stage and for the site. The first being hand surveying, especially for those heritage structures that have never been recorded previously. This method allows for tangible and intangible aspects of heritage to be sketched, drawn and represented in different forms (collage, orthographic drawings, paintings, photographs). 
Following this method, the photogrammetry method can be utilized in conjunction with the hand surveying method to gain photorealistic objective information like measurements. Such objective information allows for the data to be processed for use by conservationists and architects to redevelop/maintain the heritage structure. What's more is the architect/conservationist would not only have objective information to use for planning/building work but also make sympathetic decisions due to the availability of the representations output as a result of hand surveying and onsite experience of the heritage urban environment. When a structure or detailing is complex, laser scanning can be used as part of the third step that can allow for an advanced understanding of structure, details of façade and surfaces and access to measurements of otherwise inaccessible areas. This three-step method allows for three methods of capture and representation of heritage to be interconnected and enables the advantages and disadvantages of each method to be overcome. Overall, this three-step framework for heritage structures in Diu Town can be used in its entirety - stage 1-3 or stage 1-2 or stage 1 - only depending on what is required off a heritage environment project.

\subsection{Heritage interpretation}

Heritage interpretation has taken the form of several activities conducted by a group or as individuals, between heritage owners and by owners who have come forward to invite and educate visitors and tourists about their heritage. Some traditional forms of heritage interpretation have been through publications, guidebooks, leaflets and onsite information on signs, explanatory boards or digital displays. In person, interpretation has taken the form of guided or audio tours around a site by heritage owners or historian/expert. Furthermore, interpretations have also taken the form of plays and enactments of a historical scene or event within the heritage site [14]. In recent times, as digital simulation has taken on a larger role in creating remote heritage interpretation experiences that can help to inform the heritage owners of the values of their own heritage better so that demolition of heritage can be replaced with development and conservation of it.

In most cases, the intangible heritage values, like those of social and cultural realms which are explained through narratives and speaking to inhabitants of the heritage property, are missing. Architectural representation these days has become increasingly photorealistic, just like the photosphere, photogrammetry and laser scanning methods of capture that were covered in this paper. The continuous need to make representations as realistic as possible has resulted in creating copies of reality rather than critical responses of the real world. With the exception of traditional surveying, other capture methods are an automated process in which images of the real heritage structure are processed to create/simulate a parallel reality, called virtual reality. The one point about the traditional methods of a survey which today is seen as a disadvantage is the incorporation of a drawing/painting style which is probably the one that is most useful to truly interpret the values of the heritage structure.

\subsection{Representation of heritage architecture}

The idea of the narrative of the building that is usually missing within modern-day virtual models along with the draftsman's interpretation which serves a highly important role in making the interpretation of privately owned heritage available for layman/heritage owners to be inspired by. Every building has its own story and narrative $[15,16]$ and various facets of its past that it holds, all of which can be represented through its representative orthographic 
drawings - the architectural section. The representation technique of the section has the ability to show the past, present and the possible future of the heritage structure as a superimposition layered drawing mixed media piece. This is further explored when the plan is also investigated for its inherent and possible capacity to facilitate the representation of not only the present but past $[17,18]$. More recently in an article by C.J. Lim titled 'London Short Stories Drawing Narratives' [19], it is stated that the current generation is losing patience in critically analysing, reading its subtexts or focusing on an intended ambiguities in a piece of work. This issue is particularly strong within architecture as any critical analysis does not go beyond the form and apparent appearance. Furthermore, he states how reading a building has become so rare that in fact, it seems as though buildings cannot be read and have been designed with no signified meaning, or symbolism in buildings of antiquity. It is interesting and also relatable to Goffi when Brown [20] speaks of how the narrative story of the building can be used in economically challenging times. The conversation turns towards the use of the narrative story for remodelling or renovating the building where the narrative can be used to develop a new narrative for the remodelling or the old narrative can be totally transformed for the adaptive reuse of the heritage structure.

\section{DIRECTION FOR THE FUTURE}

Within the larger scope of the research project, the findings of this paper serve as a tool by which to progress into testing the methods of representation of heritage values within today's technologically driven and photorealistic hungry society. The evaluation in Sections 3 and 4 allows this paper to inform the overall research that the first stage of capturing and recording heritage should be the hand surveying method. Hand surveying can be easily carried out in Diu Town in conjunction with some simple photogrammetric techniques in order to collect and record tangible objective elements like physical heritage structures and their measurements. In addition, collecting and recording intangible heritage elements can be done by conducting interviews with heritage owners. The capturing and recording of tangible and intangible heritage information through hand surveying, photogrammetry and interview methods inevitably bring in the discussion of the representation of the heritage data from Section 4.3 where the narrative and story of the architectural section is a key element. This will lead the research to explore and experiment with the methods of representation of heritage urban environments that incorporate not only objective outcomes (orthographic drawings/virtual models) for architects and conservationists to work with but also enable the representation of the narratives of the heritage owners, the ambiance and essence of the place and intangible elements that help to make considerate and sympathetic decisions for future building/conservation/redevelopment of the heritage environment.

The current and future generations who own built heritage in Diu Town need a process that leads to a representations of the holistic values of heritage; historical, social, cultural, financial, etc. It is this method/combination of capture and interpretation/representation methods of heritage that are being investigated by the researcher within the research project to enable a much more forward-looking and critical approach of built opportunities for architectural heritage. This would be where the interpretation is an inspiration towards the physical manifestation of developing or conserving the heritage that lies in ruins or is in consideration for demolition. 


\section{ACKNOWLEDGEMENTS}

I am thankful to Dr Douglas Cawthorne due to whom I was able to carry out laser scanning on St Mary de Castro (Leicester, UK). I am thankful to my supervisors Dr Yuri Hadi, Dr Elizabeth Lambourn and Prof. Peter Ford for their ongoing support. The first trip to Diu Island would not have been possible without Cantilal Meggi, Ketan Jethwa and Vijay Camaldas, the locals who opened up their homes among many others who supported the research.

\section{REFERENCES}

[1] Rossa, W., Mattoso, J., da Cunha, M.S., Matias, M.F., Faria, A.S., Fundação Calouste, G., Portuguese Heritage Around the World, Asia Oceania, Calouste Gulbenkian Foundation: Lisbon, 554 pp., 2011: illustrations (chiefly colour), colour.

[2] Shokoohy, M.\& Shokoohy, N.H., The island of Diu, its architecture and historic remains. Journalof SouthAsian, 26(2),pp. 161-191,2010. DOI: 10.1080/02666030.2010.514743.

[3] Shokoohy, M., Shokoohy, N.H., The town of Diu, its churches, monasteries and other historic features. Journal of South Asian, 23(1), pp. 141-188, 2007. DOI: 10.1080/02666030.2007.9628673.

[4] Shokoohy, M., Shokoohy, N.H., The Portuguese fort of Diu. Journal of South Asian, 19(1), pp. 169-203, 2003. DOI: 10.1080/02666030.2003.9628628.

[5] dos Santos, J.R., Mendiratta, S.L., Goa, Damão e Diu aos Olhosde Resende: Análise Comparativa das Vistas Representadas. Oriente, (20), pp. 51-62, 2011, available at https:// www.academia.edu/1128752/Goa_Damão_e_Diu_aos_Olhos_de_Resende_Análise_ Comparativa_das_Vistas_Representadas_Goa_Daman_and_Diu_as_seen_by_Pedro_ Resende_A_Comparative_Analysis_of_his_Cityscapes_(accessed 31 August 2016).

[6] Mendiratta, SL., Sistemas defensivos das Ilhas de Tiswadi e Diu Ocupação e fortificação de dois territórios insulares da Índia portuguesa (Séc. XVI-XVIII), Vol. 2016, available at http://vitruvius.com.br/revistas/read/arquitextos/12.143/4323 (accessed 1 September 2016), 2012.

[7] Mendiratta, S.L., Dispositivos do Sistema Defensivo da Província do Norte do Estado da Índia, 1521-1739, Departamento de Arquitectura da Faculdade de Ciências e Tecnologia da Universidade de Coimbra, Coimbra University: Coimbra, 2012.

[8] Cachado, R.A., Locating Portuguese Hindus: transnationality in urban settings. Sociologia, Problemas e Práticas, Vol. 76, available at http://spp.revues.org/1730 (7 April 2017), 2014.

[9] Cachado, R., Beyond Martim Moniz: Portuguese Hindu Gujarati Merchants in Lisbon, Vol. 21, Etnográfica, available at https://etnografica.revues.org/4871\#quotation (1 August 2017), 2017.

[10] International GIM, Crowdsourcing the Reconstruction of Lost Heritage, Vol. 2017, available at https://www.gim-international.com/content/article/crowdsourcing-the-reconstruction-of-lost-heritage (27 June 2017), 2016.

[11] Fabola, A., Miller, A., Fawcett, R., Exploring the past with Google Cardboard. 2015 Digital Heritage, IEEE, pp. 277-284, 2015. DOI: 10.1109/DigitalHeritage.2015.7413882.

[12] Google Arts \& Culture, Vol. 2016, available at https://www.google.com/culturalinstitute/beta/ (12 September 2016), 2016. DOI: 10.1109/DigitalHeritage.2015.7413882.

[13] Zilliacus, A., 10 Models Which Show the Power of Point Cloud Scans, As Selected by Sketchfab, Vol. 2016, available at http://www.archdaily.com/798877/10-models-whichshow-the-power-of-point-cloud-scans-as-selected-by-sketchfab (accessed 12 November 2016), 2016. 
[14] Tilden, F., Interpreting Our Heritage, University of North Carolina Press: Chapel Hill, available at https://books.google.co.uk/books?id=dDiPX4sDBekC (10 August 2016), 1967.

[15] Ampatzidou, C., Molenda, A., Building Stories - The Architectural Design Process as Narrative, Digital Storytelling in Times of Crisis, available at http://www.cristinaampatzidou.com/building-stories-the-architectural-design-process-as-narrative-conference-paper/ (accessed 3 August 2017), 2014.

[16] Emmons, P., Feuerstein, M.F., Dayer, C., Confabulations: Storytelling in Architecture, Taylor \& Francis, available at https://books.google.co.uk/books?id=R4a_DQAAQBAJ (accessed 4 August 2017), 2016.

[17] Goffi, F., Time Matter(s): Invention and Re-imagination in Built Conservation: The Unfinished Drawing and Building of St. Peter's, the Vatican, Ashgate: Farnham, Surrey, England; Burlington, CT, xix, 255 pp., 2013: illustrations; 25.

[18] Goffi, F., Drawing imagination and the imagination of drawing. Interstices, (11), pp. 20-30, 2014, http://interstices.ac.nz/previousfiles/INT11_Goffi.pdf (accessed 20 November 2016).

[19] Lim, C.J., London short stories: drawing narratives. Architectural Design, 83(5), pp. 102-107, 2013. DOI: 10.1002/ad.1641.

[20] Brown, AW., Storytelling in Architecture, Vol. 2017, Planetizen, available at https:// www.planetizen.com/node/46878 (accessed 3 August 2017), 2010. 